\title{
Morphological modelling of intertidal mudflats: the role of cross-shore tidal currents
}

\author{
D. Pritchard ${ }^{\mathrm{a} *}$, A.J. Hogg ${ }^{\mathrm{a}}$, W. Roberts ${ }^{\mathrm{b}}$ \\ ${ }^{a}$ Centre for Environmental and Geophysical Flows, Department of Mathematics, University of Bristol, Bristol BS8 1TW, UK \\ ${ }^{\mathrm{b}}$ H.R. Wallingford Ltd., Howbery Park, Wallingford OX10 8BA, UK
}

Received 23 November 2001; accepted 3 December 2001

\begin{abstract}
We describe a mathematical model of the sediment transport resulting from cross-shore tidal currents on an intertidal mudflat. The model is integrated numerically to determine the long-term ("equilibrium") behaviour of the morphodynamic system, and to investigate how the morphology of the flats depends on tidal range and sediment supply.

Under a sinusoidal tide, the equilibrium flat is approximately linear below mean sea level (MSL) and convex above MSL, and advances seawards over long timescales. The cross-shore width of the flat is independent of tidal range, and increases with increasing sediment supply. Tidal asymmetry (flood- or ebb-dominance) leads to a steeper flat, and ebbdominance can cause the flat to retreat landwards in the long term. Under a spring-neap tidal cycle, the shape of the equilibrium profile is very similar to that for a fixed tidal range, but the rate of accretion is significantly reduced. (C) 2002 Elsevier Science Ltd. All rights reserved.
\end{abstract}

Keywords: Estuaries; Intertidal mudflats; Intertidal sedimentation; Mathematical models; Morphodynamics

\section{Introduction}

The systematic study of the morphology of intertidal mudflats has been rather neglected in comparison to that of sandy beaches. It is only in the last decade that a number of systematic empirical studies (Kirby, 1992; Dyer, 1998; Kirby, 2000) have been made to determine which forms of external forcing are crucial in developing and maintaining the observed "equilibrium" morphologies.

The cross-shore profiles of mudflats can be classified according to the relative contributions

*Corresponding author. made by wind waves and tidal currents to the total sediment transport (Kirby, 2000). At one end of the range are erosional flats dominated by windgenerated waves, which are characterised by a concave-upwards profile, while at the other end are tidally dominated flats with a convex-upwards profile, which are believed to have a tendency to accrete over long times.

This paper is concerned with flats which evolve under purely tidal forcing. Most real mudflats, with the possible exception of those in extremely sheltered estuarine environments, are influenced both by tidal currents and by the action of surface waves in both mobilising and transporting sediment (Lee and Mehta, 1997; Le Hir et al., 2000). 
However, this idealisation allows us to make significant progress towards understanding and characterising the processes which occur under tidal forcing, and this provides a starting point for understanding the more complex dynamics of flats under combined forcing.

Previous modelling studies of tidally dominated flats were carried out by Friedrichs and Aubrey (1996) and by Roberts et al. (2000), while Lee and Mehta (1997) have provided a review of many of the issues involved (although their emphasis was on wave-dominated flats). With the exception of a single numerical experiment presented by Roberts et al. previous modelling studies have made the simplifying assumption of neglecting the effects of fluid inertia, with velocities being determined purely by fluid continuity. This is a good firstorder approximation, but by neglecting the possibility of dynamical asymmetry between the flood and ebb tides, it may exclude some important sediment transport processes.

Friedrichs and Aubrey (1996) sought an analytical description of an equilibrium flat. This was taken to correspond to a flat on which peak shear stress (and thus peak velocity during a tidal cycle) was uniformly distributed across the flat. From this assumption, and taking a sinusoidal tidal elevation curve, it is straightforward to derive the profile

$d(x)= \begin{cases}-\frac{1}{2} \eta_{0}\left(x / L_{c r i t}-1\right) & \text { for } x \leqslant L_{\text {crit }}, \\ -\frac{1}{2} \eta_{0} \sin \left(x / L_{\text {crit }}-1\right) & \text { for } x \geqslant L_{\text {crit }} .\end{cases}$

Here low water (LW) occurs at $x=0$, and $L_{c r i t}=$ $U_{\text {crit }} / \omega$, for $\omega$ the angular frequency of tidal forcing and $U_{\text {crit }}$ the maximum velocity reached during the tidal cycle. We shall refer to this profile as an FA96-flat.

The FA96-profile provides a good qualitative model for the tidally dominated flats described by Kirby (2000); however, as Lee and Mehta (1997) point out, muddy sediments are easily transported long distances in suspension, and so it may be misleading to consider equilibrium in terms of a local balance.

Roberts et al. (2000) calculated numerically the currents and sediment transport with morphodynamic feedback, iteratively updating the bed profile according to the net erosion or deposition at each point, and obtained equilibrium profiles under various forcing conditions. The profiles obtained resembled those of Friedrichs and Aubrey (1996), but tended to develop an extensive, gently sloping upper flat on which unrealistically high velocities occurred. They saw no evidence of long-term accretion or erosion of their flats once an equilibrium profile had been reached.

The model which we develop is an extension of that of Roberts et al. (2000), including more complete dynamics, and integrated using a numerical method (CANUTE) which has been designed to represent the dynamics accurately in very shallow water, in order to avoid the physically unrealistic velocities seen by Roberts et al. We compare our results with analytical predictions, obtained by extending the work of Friedrichs and Aubrey (1996), which are described in more detail elsewhere (Pritchard and Hogg, 2001).

\section{Description of the model}

The prototype for our model is a macrotidal flat of the type common in north-western Europe, and our choice of physical parameters reflects this. However, the model is sufficiently general for our results to have a wider application. We consider forcing solely by cross-shore tidal currents, noting that it is only in deeper water that longshore flows are likely to dominate the sediment transport (Le Hir et al., 2000).

The model geometry is shown in Fig. 1. We consider water depth $h(x, t)$, depth-averaged

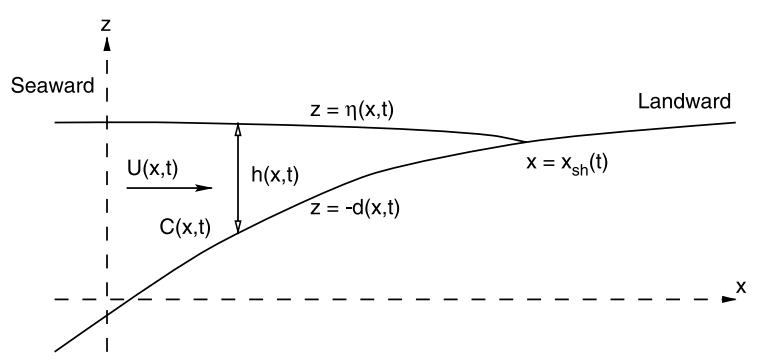

Fig. 1. Definition diagram for cross-shore model (vertically exaggerated for clarity). 
velocity $U(x, t)$, bed elevation $z=-d(x, t)$, water surface elevation $z=\eta(x, t)$ and depth-averaged suspended sediment mass concentration (SSC) $C(x, t)$.

We model cross-shore tidal currents using the one-dimensional shallow-water equations (Peregrine, 1972). To represent the effects of friction, we use a quadratic drag law with a constant friction coefficient. After scaling with respect to tidal period $T$, tidal range $\eta_{0}$ and a scale $U_{0}$ of "typical" cross-shore velocity, the nondimensionalised equations for mass and momentum have the form

$\frac{\partial h}{\partial t}+\frac{\partial}{\partial x}(U h)=0$

$\frac{\partial U}{\partial t}+U \frac{\partial U}{\partial x}=-\frac{1}{F^{2}} \frac{\partial}{\partial x}(h-d)-K \frac{|U| U}{h}$,

where $F \equiv U_{0} / \sqrt{\eta_{0} T}$, the global Froude number, is of order $1 / 30$, and the dimensionless friction coefficient $K \equiv c_{D} T U_{0} / \eta_{0}$ is of order 1. (In order for both erosional and depositional processes to be significant, $U_{0}$ must be of similar magnitude to $U_{e}$, the threshold velocity for sediment erosion.)

The boundary condition on the hydrodynamics is an incoming tidal characteristic imposed at the seaward boundary, while the shoreline boundary is free to move.

The sediment is considered as being transported in suspension, and over the relevant length- and time-scales this transport will be purely advective. Erosion and deposition rates are modelled using the Partheniades and Krone formulae (Dyer, 1986). In nondimensionalising the equation, the scale for suspended sediment concentration is given by $C_{0} \equiv m_{e} / w_{s}$, where $m_{e}$ is the mass erosion rate and $w_{s}$ a typical settling velocity of the suspended flocs. This represents a "reference" concentration defined by an order-of-magnitude balance between erosion and deposition.

In its nondimensionalised form, the sediment transport equation has the form

$$
\frac{\partial C}{\partial t}+U \frac{\partial C}{\partial x}=\frac{E}{h}\left[Q_{e}(U)-Q_{d}(U, C)\right],
$$

where

$$
\begin{gathered}
Q_{e}= \begin{cases}\left(\frac{U^{2}}{U_{e}^{2}}-1\right) & \text { for }|U| \geqslant U_{e}, \\
0 & \text { for }|U|<U_{e},\end{cases} \\
Q_{d}= \begin{cases}C\left(1-\frac{U^{2}}{U_{d}^{2}}\right) & \text { for }|U| \leqslant U_{d}, \\
0 & \text { for }|U|>U_{d} .\end{cases}
\end{gathered}
$$

The parameters $U_{e}$ and $U_{d}$ are the threshold velocities for erosion and deposition respectively, and $E \equiv T w_{s} / \eta_{0}$ is the nondimensional bed exchange rate, which is typically of order 10 .

We follow Roberts et al. (2000) in imposing a constant "far-field" concentration $C=C_{b d y}$ at the seaward boundary during the flood tide. While this choice of boundary condition is suitable for the generic model described here, it seems likely that the phasing of the sediment supply relative to the cross-shore currents could affect both the shape and the accretionary behaviour of a flat. However, this lies outwith the scope of the present study.

The morphodynamic equations are completed by the bed evolution equation

$\frac{\partial d}{\partial t}=r E\left[Q_{e}(U)-Q_{d}(U, C)\right]$,

where $r \equiv C_{0} / C_{\text {bulk }}$ is the ratio of sediment concentration in the water column to that in the bed, and corresponds to a dimensionless bed evolution rate which is typically of order 0.0001 .

In choosing the components of this model, our aim has been to represent the dynamical effects as simply as possible, and yet still to capture the essential physical processes. More complicated models of the boundary shear stress and sediment transport could be employed to provide a closer correspondence with field data. In particular, we assume that sediment properties are constant across the flat, and that the surface properties of the sediment are always the same (in other words, we neglect consolidation and dewatering effects). As with our other simplifications, it appears that the effects of sediment heterogeneity are not essential to produce realistic morphodynamic results. 


\section{Numerical experiments}

Eqs. (2)-(7) were solved numerically using a custom-built solver, CANUTE. The procedure for each numerical experiment was to start with a linear or FA96 profile and simply to allow it to evolve under constant forcing conditions until an apparent equilibrium state developed. This typically took between 10000 and 40000 tides, and the results did not depend on the form of the initial profile.

The physical parameters used in all the experiments were $\tau_{e}=0.2 \mathrm{~N} \mathrm{~m}^{-2}, \quad \tau_{d}=0.1 \mathrm{~N} \mathrm{~m}^{-2}$, $w_{s}=10^{-3} \mathrm{~m} \mathrm{~s}^{-1}$, erosion rate $m_{e}=5 \times$ $10^{-5} \mathrm{~kg} \mathrm{~m}^{-2} \mathrm{~s}^{-1}$ and $c_{D}=0.006$. With the exception of the friction coefficient $c_{D}$, they are taken from Roberts et al. (2000), and are typical of the properties of mudflats in north-western Europe. The drag coefficient $c_{D}$ was chosen to be at the upper end of physically plausible values, to ensure that any crucial dynamical effects of friction would be apparent.

\subsection{No sediment supply}

When there is no external supply of sediment, the only way in which equilibrium can be achieved is for the flats to adapt to a static situation where no sediment is eroded or deposited at any point on the flat throughout the cycle. The marginal

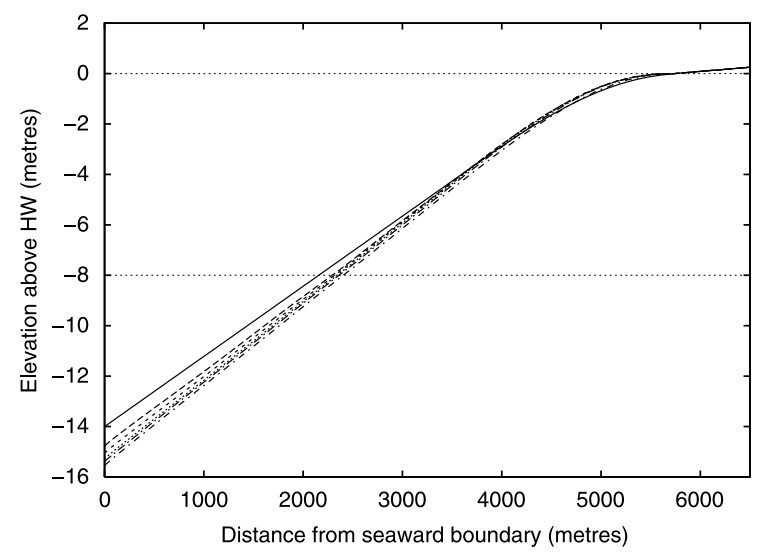

Fig. 2. Bed profiles at 0 (-), 12000 (--), 24000 (- -), 48000 $(\cdots), 72000(--), 120000(---)$ tides for a tidal range of $8 \mathrm{~m}, C_{b d y}=0$. profile where this is possible is given approximately by the FA96 profile with $U_{\text {crit }}=U_{e}$. Fig. 2 shows a flat evolving from an initial profile where $U_{\max }>U_{e}$, under the forcing conditions $\eta_{0}=8 \mathrm{~m}$ and $C_{b d y}=0$, and the envelopes of maximum flood and ebb velocity on the initial and nearequilibrium flats are shown in Fig. 3. This figure illustrates the gradual adjustment of the profile so that the maximum velocity reduces from around $0.21 \mathrm{~m} \mathrm{~s}^{-1}$ on the initial flat to around $0.185 \mathrm{~m} \mathrm{~s}^{-1}$ on the near-equilibrium flat - as might be expected, the condition $U_{\max }=U_{e}$ provides a good description of the equilibrium dynamics.
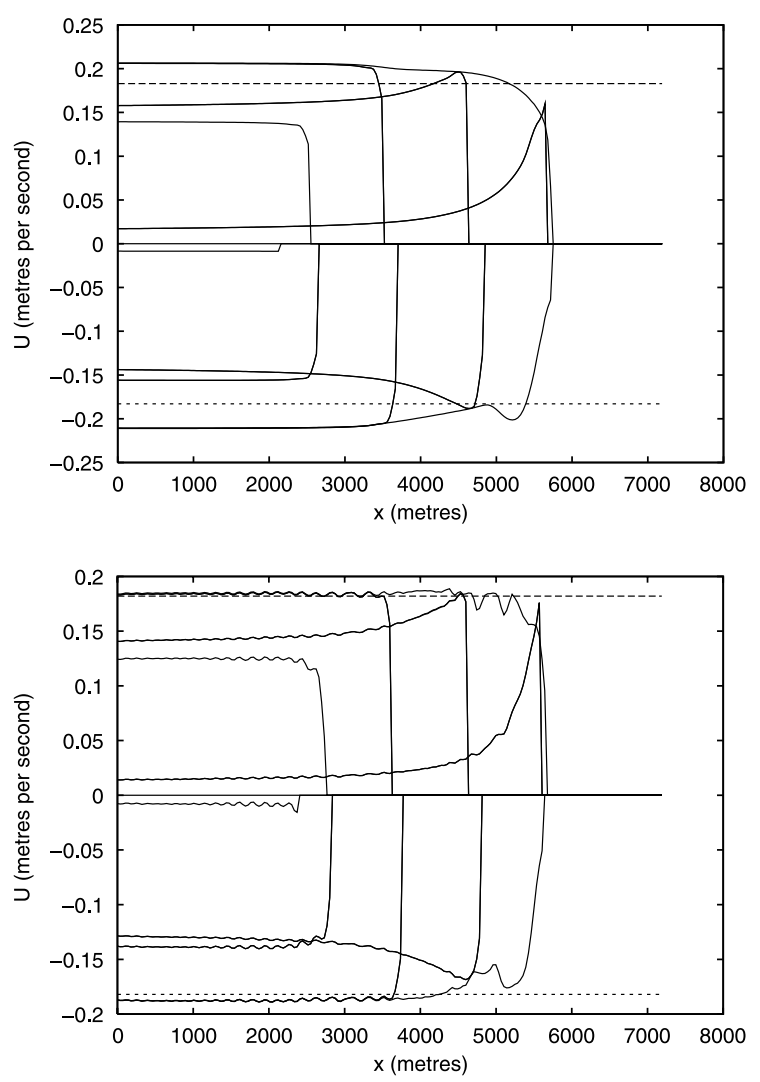

Fig. 3. Velocity "snapshots" at $t=n / 8$ (tidal period), and envelope of maximum flood and ebb velocity, on (i) a flat some way from static equilibrium and (ii) a flat which has nearly reached static equilibrium. (Here and subsequently, $U>0$ corresponds to shorewards flow.) Also shown are $\pm U_{e}$. The small oscillations in the velocity field correspond to genuine small-scale fluctuations in the bed profile: they are nonincreasing and are not the result of numerical instability. 


\subsection{External supply of sediment}

Experiments were carried out for $C_{b d y}=$ $0.1 \mathrm{~kg} \mathrm{~m}^{-3}$ with $\eta_{0}=4,6$ and $8 \mathrm{~m}$, and for $\eta_{0}=$ $8 \mathrm{~m}$, with $C_{b d y}=0.025,0.1,0.2$ and $0.4 \mathrm{~kg} \mathrm{~m}^{-3}$. These are the same conditions as those used by Roberts et al. (2000), and cover most of the regimes observed on north-west European macrotidal flats.

Fig. 4 shows the flat profile at various stages during a typical experiment. The pattern is that the overall shape of the flat adjusts quite quickly (over the first few thousand tides); this is followed by a period of slower adjustment and finally by a longterm state where the shape of the profile is no longer adjusting, but the flat as a whole is accumulating sediment and advancing seawards. Because the model only deals with the region below HW, this long-term progradation means that a "plateau" develops precisely at the HW mark. Due to frictional and inertial effects, the "plateau" region is never inundated, and its development involves sub-aerial physical and biological processes which lie outwith the scope of our model. (We note in passing that in the model of Roberts et al., which did not include inertia or friction, it was impossible for such a feature to develop without causing implausibly large velocities on the upper flat: this may explain some of the differences between our results and theirs in this region.)

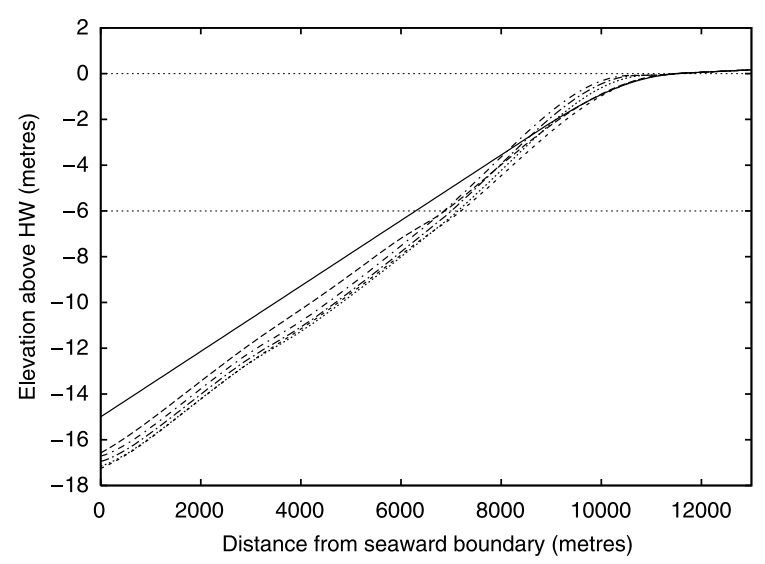

Fig. 4. Tidal range $6 \mathrm{~m}, C_{b d y}=0.1 \mathrm{~kg} \mathrm{~m}^{-3}$, plots every 6000 tides. Initial profile (-); latest profile (---).

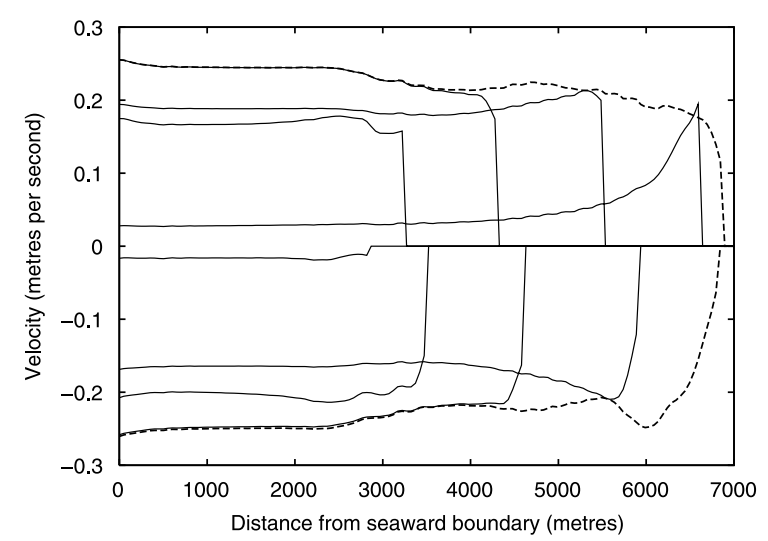

Fig. 5. Velocity plotted against $x$, for tidal range $6 \mathrm{~m}, C_{b d y}=$ $0.1 \mathrm{~kg} \mathrm{~m}^{-3}$, at $t=n / 8$ (tidal period). Also plotted are "envelopes" (- $)$ of maximum flood and ebb velocity.

Fig. 5 shows snapshots of the velocity field on the equilibrium flat at several instants during a tidal cycle, as well as "envelopes" of maximum velocity during the flood and ebb phases. Despite the greater complexity of our model than that of Friedrichs and Aubrey (we include both nonlinear terms and explicit sediment supply), it is apparent that the condition $U_{\max }=$ constant provides a reasonable first-order description of the equilibrium dynamics. The shape of the profile, which is convex-upwards above MSL and approximately linear below MSL, is also in accordance with the FA96 model, as well as with the numerical results of Roberts et al. (2000), and with the profiles described by Kirby (2000).

We note that inertial effects on the convex flat lead to a slight ebb-dominance of the currents (most visible in the "envelope" plots in Fig. 3), even though the incoming tidal characteristic is sinusoidal. This ebb-dominance is not strong enough, however, to lead to a net export of sediment.

\subsection{Dependence on forcing conditions and comparison with theoretical predictions}

The results of our numerical experiments allow us to describe the effect of tidal range and sediment supply on the equilibrium morphology of our model flats. The overall morphology can be 
described by the parameter $U_{\max }$, which is proportional to the length of the flats between LW and HW, and which is almost constant across the flat. (Where there is some variation, we have taken $U_{\max }$ to be the maximum velocity reached within the computational domain: this generally occurs below MSL). In Table 1, we summarise the results of our experiments, and compare the theoretical predictions of Pritchard and Hogg (2001) for the same conditions.

We note first that $U_{\max }$ does not vary significantly with tidal range. This can also be seen in Fig. 6, where the equilibrium profiles for $\eta_{0}=8,6$ and $4 \mathrm{~m}$ are plotted so that $x=0$ corresponds to low water: it is evident that the length of the flats between LW and HW is the same in each case. The theoretical predictions, and the results of Roberts et al., also agree with this finding.

As sediment supply increases, higher velocities across the flat are required to maintain more sediment in suspension, and thus the equilibrium flats are of lower gradient. This can be observed in the results presented in Table 1, and it is also evident in Fig. 7, where the equilibrium profiles for four different sediment supplies and a constant tidal range are plotted so that the LW marks coincide.

Our theoretical predictions agree with this result qualitatively, though the results progressively diverge from the predictions for higher values of $C_{b d y}$. This is because on the more gently-sloping flats which develop, the role of inertial and frictional terms, which are neglected in the analysis, is more important. (However, the error is still within about $10 \%$.)

Table 1

Maximum current speeds for equilibrium flats, compared with theoretical predictions $U_{\text {crit }}$. Relative errors $\left(U_{\text {crit }}-U_{\max }\right) / U_{c r i t}$ are shown in square brackets

\begin{tabular}{llll}
\hline$\eta_{0}(\mathrm{~m})$ & $C_{b d y}\left(\mathrm{~kg} \mathrm{~m}^{-3}\right)$ & $U_{\max }\left(\mathrm{ms}^{-1}\right)$ & $U_{\text {crit }}\left(\mathrm{m} \mathrm{s}^{-1}\right)$ \\
\hline 8 & 0.025 & 0.226 & $0.223[-0.013]$ \\
8 & 0.1 & 0.262 & $0.273[0.040]$ \\
8 & 0.2 & 0.287 & $0.305[0.059]$ \\
8 & 0.4 & 0.329 & $0.366[0.101]$ \\
6 & 0.1 & 0.256 & $0.273[0.062]$ \\
4 & 0.1 & 0.256 & $0.273[0.062]$ \\
\hline
\end{tabular}

\section{Extensions}

\subsection{Flood- and ebb-dominated tides}

An obvious extension of the numerical experiments is to consider what happens when the imposed tide is no longer sinusoidal. We expect that a strongly flood- or ebb-dominated regime ought to create a steeper flat, since the nonlinear nature of sediment transport means that it is the

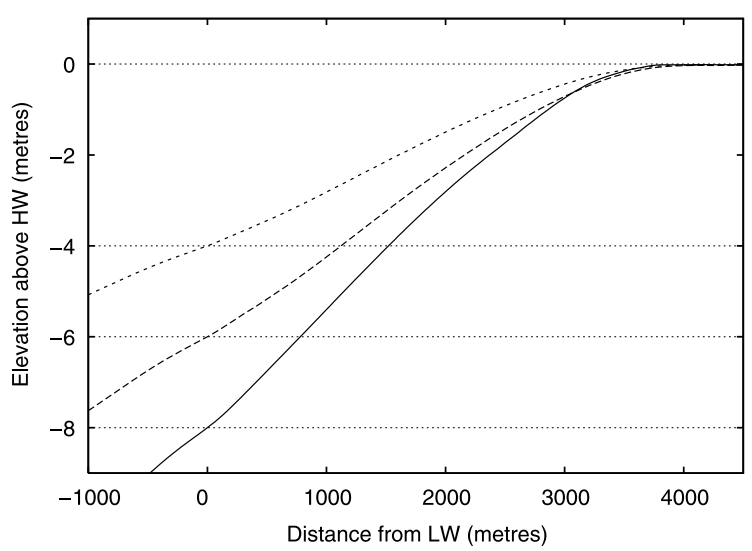

Fig. 6. Equilibrium bed profiles for boundary suspended sediment concentration $C_{b d y}=0.1 \mathrm{~kg} \mathrm{~m}^{-3}$, tidal range $8 \mathrm{~m}$ (一), $6 \mathrm{~m}(--), 4 \mathrm{~m}(--)$.

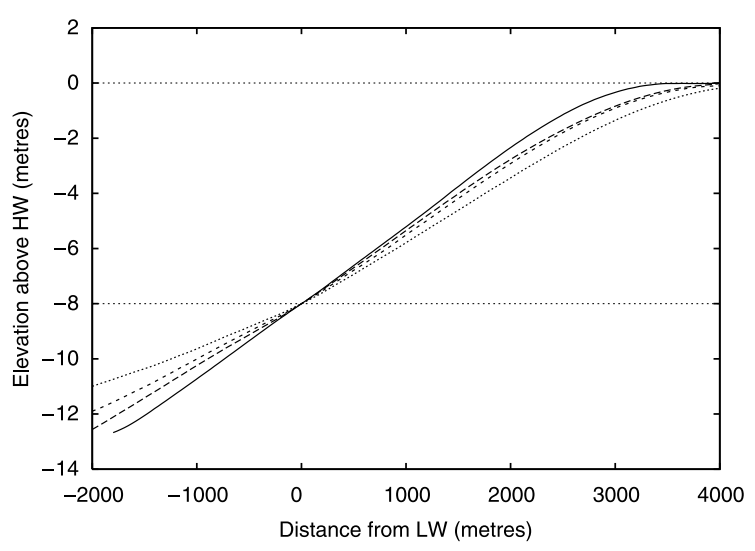

Fig. 7. Equilibrium bed profiles for tidal range $8 \mathrm{~m}$, boundary suspended sediment concentration $0.025 \mathrm{~kg} \mathrm{~m}^{-3} \quad(-)$, $0.1 \mathrm{~kg} \mathrm{~m}^{-3}(--), 0.2 \mathrm{~kg} \mathrm{~m}^{-3}(--), 0.4 \mathrm{~kg} \mathrm{~m}^{-3}(\cdots)(x$-axes shifted so LW coincide). 
maximum rather than the average current velocity which is most significant in determining the morphology.

Experiments were carried out with a boundary sediment concentration of $0.1 \mathrm{~kg} \mathrm{~m}^{-3}$, using incoming tidal characteristics which correspond to the highly asymmetrical tidal elevations

$\eta(t)=\varepsilon \eta_{0}\left[\cos (2 t) \pm 0.25 \cos \left(4 t+\frac{\pi}{2}\right)\right]$

(respectively, flood- and ebb-dominated tides), where $\varepsilon=0.454$ is chosen such that the amplitude of the elevation curve is $\eta_{0}$.

The evolution of the profiles is shown in Figs. 8 and 9, and the envelopes of maximum flood and ebb velocity are shown in Fig. 10. It can be seen that the form of the equilibrium profiles is still reasonably well described by the assumption of uniform peak stress, and in fact the value of $U_{\max }$ is reasonably well predicted by the theory of Pritchard and Hogg (2001), which suggests that when a symmetrical tide is imposed on the flat, $U_{\max }$ should equal $0.244 \mathrm{~m} \mathrm{~s}^{-1}$. A flood-dominant regime, however, enhances the tendency for the flat to accumulate sediment and prograde, while an ebb-dominant regime leads to the export of sediment, so the flat retreats landwards over long times.

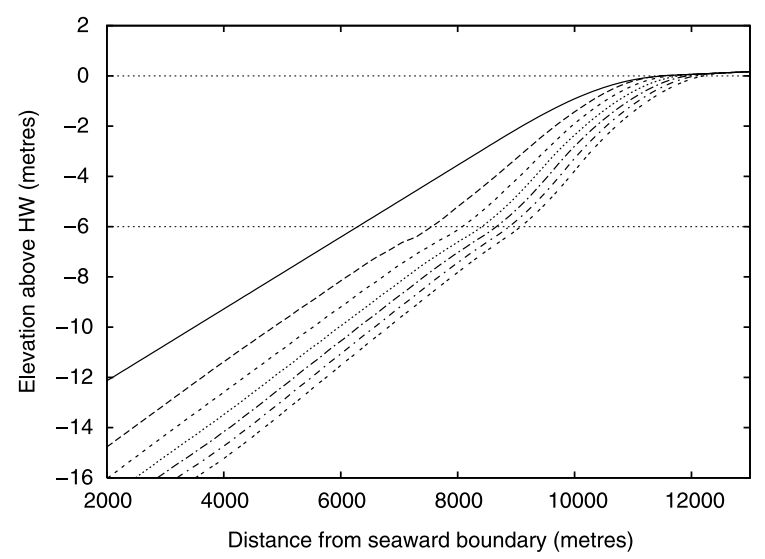

Fig. 8. Tidal range $6 \mathrm{~m}, C_{b d y}=0.1 \mathrm{~kg} \mathrm{~m}^{-3}$, ebb-dominated tide, plots every 6000 tides. Initial profile $(-)$; latest profile (- - - ).

\subsection{Spring-neap cycle}

Finally, we consider the effect of a pronounced spring-neap variation in the tidal range. This is typical of many macrotidal mudflats. Fig. 11 shows the evolution of a flat under the imposed tide

$\eta(t)=0.8 \cos (2 t)\left[1+0.25 \sin \left(\frac{t}{14}\right)\right]$

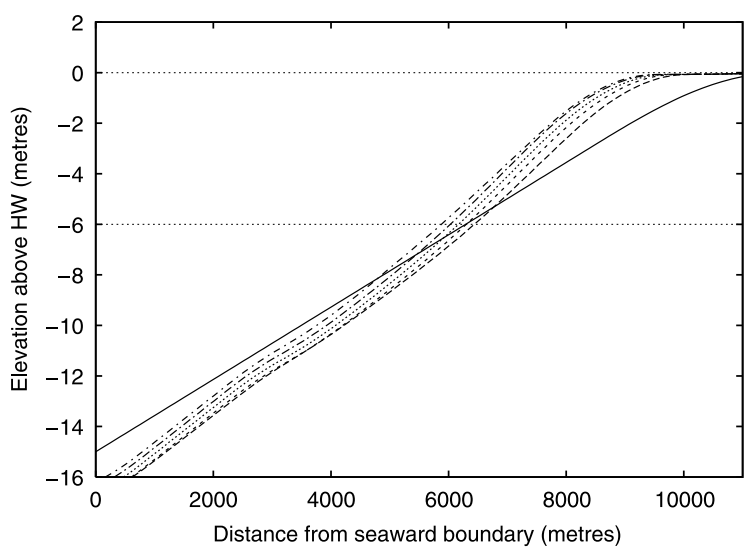

Fig. 9. Tidal range $6 \mathrm{~m}, C_{b d y}=0.1 \mathrm{~kg} \mathrm{~m}^{-3}$, flood-dominated tide, plots every 6000 tides. Initial profile (-); latest profile (---).

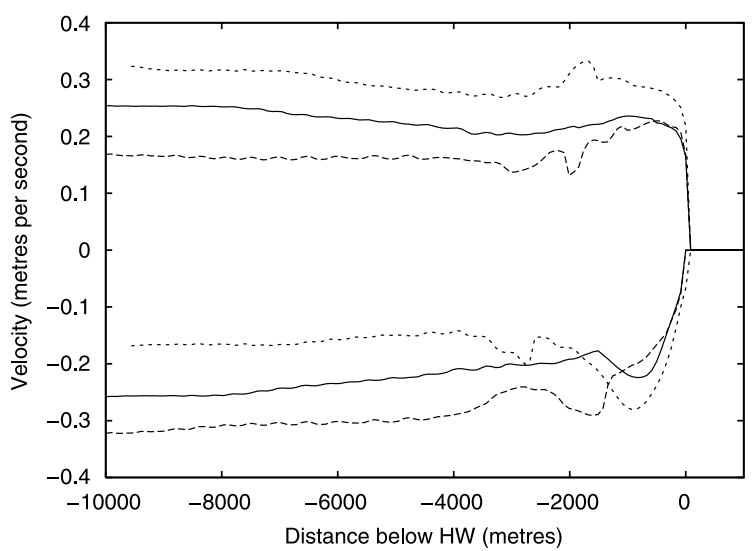

Fig. 10. Envelopes of maximum ebb and flood velocity on equilibrium flats, for boundary suspended sediment concentration $C_{b d y}=0.1 \mathrm{~kg} \mathrm{~m}^{-3}$, tidal range $6 \mathrm{~m}$ : results for symmetrical tide on ebb-dominated equilibrium flat $(-)$, ebb-dominated tide on ebb-dominated equilibrium flat $(--)$, flood-dominated tide on flood-dominated equilibrium flat (- -). 
which corresponds to spring and neap tidal ranges of 7.5 and $4.5 \mathrm{~m}$, respectively, similar to those which occur, for example, on several flats in the Severn estuary in the British Isles.

Despite the dramatic variation in tidal range, the basic profile of the flat is still very similar to that found before. An interesting difference is that the rate of progradation is significantly reducedessentially because the upper part of the flat is now inundated much less frequently and so has less opportunity to accumulate sediment. In fact, the rate of vertical accretion is now of the order of a few millimetres per year (compared to between 20 and $360 \mathrm{~mm} \mathrm{yr}^{-1}$ for single-range tides), which is a physically reasonable value (Whitehouse and Mitchener, 1998; Christie et al., 1999; O'Brien et al., 2000).

\section{Conclusions}

Despite the extremely simplified nature of our model, it is capable of reproducing the main features associated with tidally dominated equilibrium mudflats. In particular, the characteristic convex profile described theoretically by Friedrichs and Aubrey (1996) and empirically by Kirby (2000) is reproduced, and the flats are found to have a tendency to accumulate sediment over

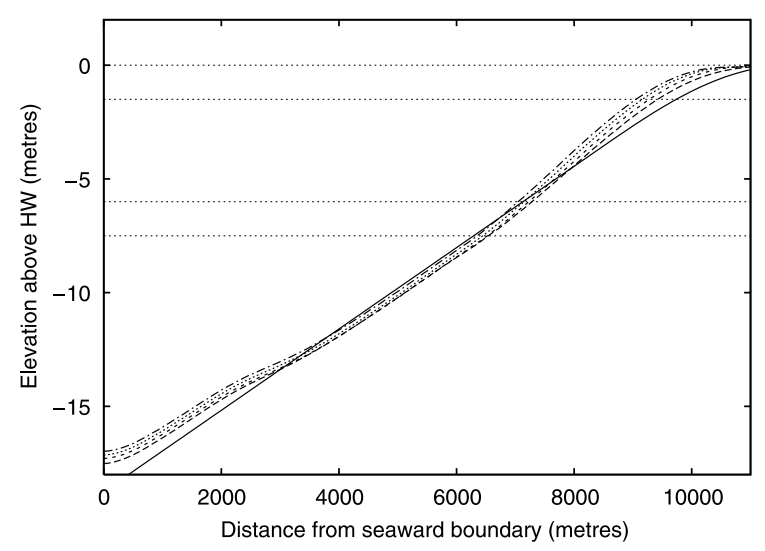

Fig. 11. $C_{b d y}=0.1 \mathrm{~kg} \mathrm{~m}^{-3}$, tidal range $4.5-7.5 \mathrm{~m}$; plots every 67200 tides. Initial profile (-); latest profile (---); also shown $(\cdots)$ are maximum and minimum tidal elevations for spring and neap tides. long times. We find that the cross-shore width of the flats is almost independent of tidal range, and increases with sediment supply, as predicted by Pritchard and Hogg (2001). We have found that flood- or ebb-dominated tides lead to a steeper equilibrium profiles, and that ebb-dominance may lead to a flat which retreats over long times. Under a spring-neap cycle, the overall character of the results is not altered, but the rate of progradation is substantially reduced (and is more similar to measured values).

The main sediment transport process involved in developing and maintaining the equilibrium state may be characterised conceptually as settling lag: since there is not a perfect symmetry between the erosion and deposition fluxes $Q_{e}$ and $Q_{d}$, there is some hysteresis in the response of suspended sediment concentration to current speeds, and the net effect of this on a fully developed equilibrium flat under symmetrical tidal forcing is to import sediment. This mechanism is discussed in more detail elsewhere (Pritchard and Hogg, 2001). This effect is observed in many tidal situations (Dyer, 1986), and over intertidal flats it appears to be associated with onshore sediment transport (Christie et al., 1999; Bassoullet et al., 2000). From this study, it is not clear why the flat adjusts such that the maximum current velocity is almost evenly distributed across it, although it seems evident that this is not the result of a local balance.

The physically realistic character of our results suggests that it may not be necessary for practical purposes to consider more "exotic" processes such as sediment consolidation, and that other effects (such as sub-aerial processes, biostabilisation or bioturbation and sediment heterogeneity) may be parameterised simply in terms of their effect on a few bulk parameters. However, issues remain which could be profitably investigated within this modelling framework: in particular, the effect of the phasing, relative to the cross-shore currents, of sediment supplied by longshore currents; and the patterns of evolution when the initial profile is very far from equilibrium (for example, for a convex initial profile). The latter might provide insight into the response of tidal flats to engineering works which significantly alter the local wave climate or tidal regime. 
The major dynamical omission from our model has been the effect of wind-generated waves in mobilising sediment. As both the Dyer and Mehby classifications (Dyer, 1998; Kirby, 2000) indicate, it is the balance between wave-driven processes and the ones described in this paper which controls the morphology of most real flats. The role of waves in mobilising sediment which is then transported by tidal currents seems likely to be particularly significant. A starting point for further study of these processes has been provided by Lee and Mehta (1997), and some simple modelling work was carried out by Roberts et al. (2000), but there remains a significant gap in our understanding of the morphodynamic effects of interacting waves and tides. However, we hope that, by clarifying both the essential processes involved in one of the two fundamental forms of forcing, and the equilibrium state reached by the system under it, we have provided the basis for the development of a more complete dynamical theory of mudflat morphology.

\section{Acknowledgements}

DP acknowledges support from the Engineering and Physical Sciences Research Council and from HR Wallingford Ltd. (Ports and Estuaries Division) under a CASE studentship. The authors would like to thank two anonymous reviewers for their constructive and helpful comments.

\section{References}

Bassoullet, Ph., Le Hir, P., Gouleau, D., Robert, S., 2000. Sediment transport over an intertidal mudflat: field investigations and estimation of fluxes within the "Baie de
Marrennes-Oleron" (France). Continental Shelf Research 20, 1635-1653.

Christie, M.C., Dyer, K.R., Turner, P., 1999. Sediment flux and bed level measurements from a macro-tidal mudflat. Estuarine, Coastal and Shelf Science 49 (5), 667-688.

Dyer, K.R., 1986. Coastal and Estuarine Sediment Dynamics. Wiley, New York.

Dyer, K.R., 1998. The typology of intertidal mudflats. In: Black, K.S., et al. (Eds.), Sedimentary Processes in the Intertidal Zone. Geological Society, London, pp. 11-24.

Friedrichs, C.T., Aubrey, D.G., 1996. Uniform bottom shear stress and equilibrium hypsometry of intertidal flats. In: Pattiaratchi, C. (Ed.), Mixing in Estuaries and Coastal Seas. American Geophysical Union, Washington, DC, pp. 405-429.

Kirby, R., 1992. Effects of sea-level rise on muddy coastal margins. In: Prandle, D. (Ed.), Dynamics and Exchanges in Estuaries and the Coastal Zone. American Geophysical Union, Washington, DC, pp. 313-334.

Kirby, R., 2000. Practical implications of tidal flat shape. Continental Shelf Research 20, 1061-1077.

Le Hir, P., et al., 2000. Characterization of intertidal flat hydrodynamics. Continental Shelf Research 20, 1433-1459.

Lee, S.-C., Mehta, A.J., 1997. Problems in characterising dynamics of mud shore profiles. Journal of Hydraulic Engineering 123 (4), 1-11.

O'Brien, D.J., Whitehouse, R.J.S., Cramp, A., 2000. The cyclic development of a macrotidal mudflat on varying timescales. Continental Shelf Research 20, 1593-1619.

Peregrine, D.H., 1972. Equations for water waves and the approximations behind them. In: Meyer, R.E. (Ed.), Waves on Beaches and Resulting Sediment Transport. Academic Press, New York, pp. 95-121.

Pritchard, D., Hogg, A.J., 2001. Cross-shore sediment transport and the equilibrium morphology of intertidal mudflats, in preparation.

Roberts, W., Le Hir, P., Whitehouse, R.J.S., 2000. Investigation using simple mathematical models of the effect of tidal currents and waves on the profile shape of intertidal mudflats. Continental Shelf Research 20, 1079 1097.

Whitehouse, R.J.S., Mitchener, H.J., 1998. Observations of the morphodynamic behaviour of an intertidal mudflat at different timescales. In: Black, K.S., et al. (Ed.), Sedimentary Processes in the Intertidal Zone. Geological Society, London, pp. 255-271. 